SPECIAL FEATURE

\section{Scouting for dental education}

\author{
By Courtney Orloff, Foundation Dentist
}

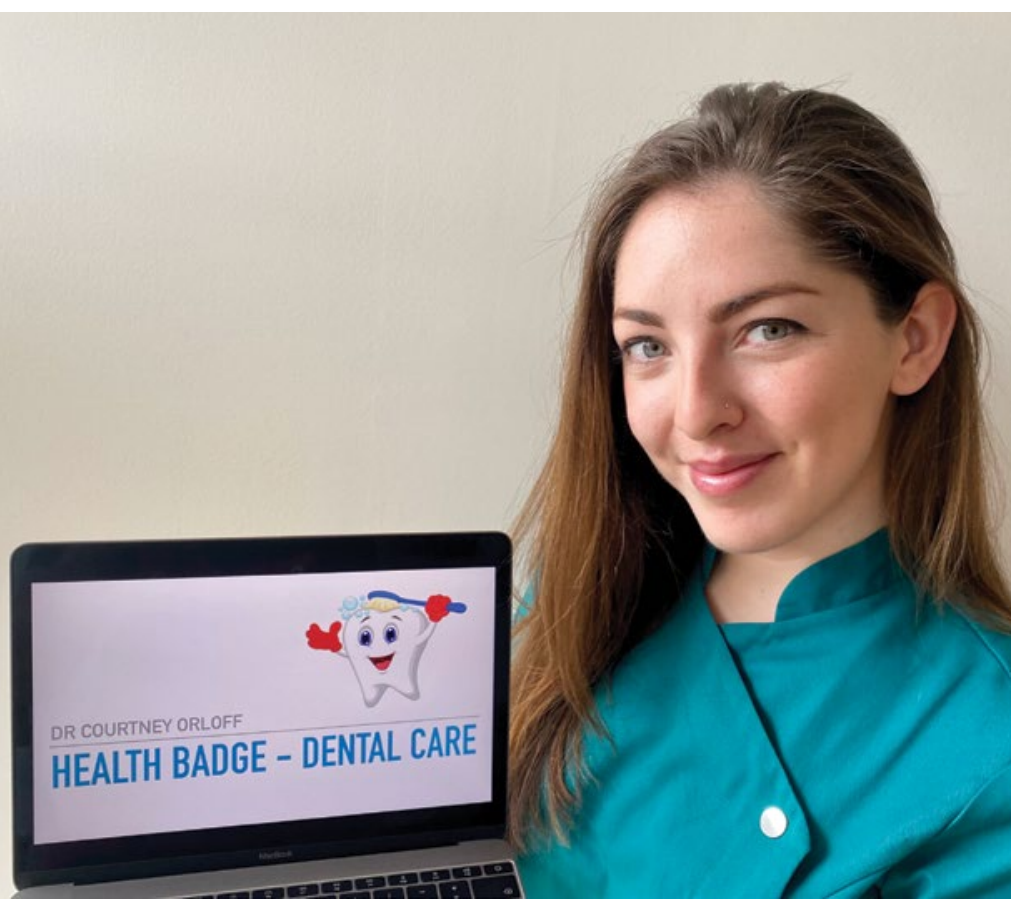

I ntroduction

The coronavirus pandemic has had an undeniable impact on the dental world, and with only limited urgent care available children are missing out on recall appointments where prevention and education play a major role. Simultaneously, since schools have closed, curriculum-based dental education and community-based oral health initiatives are also on hold. Despite these barriers, I have spent time during the lockdown delivering oral health education to children (aged between six and ten years old) over Zoom as part of an interactive online Scout meeting. The 'Zoom lesson' can easily be adapted to suit a variety of age groups and audiences, making oral health education accessible once more. Video conferencing platforms provide a valuable opportunity to keep in touch without breaking lockdown restrictions. I have drawn a number of judgements on how dental professionals can use these platforms effectively.

\section{Lockdown}

The coronavirus has had a severe impact on our way of life, both in the UK and around the world. Dentistry in particular has been drastically affected by the lockdown that was imposed in the UK on 23 March. Within a week, dental professionals went from practising as normal to having significant restrictions placed on routine dental treatment. With only urgent care available, children, who have a recommended recall of between three months and 12 months, ${ }^{1}$ are thus nearing 11 weeks without routine dental care at the time of writing. Those with reduced recalls, who are by definition at higher risk of dental health issues, are all therefore due to see a dentist. For some, recall appointments would have occurred in the early days of lockdown, meaning their last appointment could be up to six months ago, rendering them well overdue to see a dentist. Given that physical trips to the dentist cannot occur, and also that prevention remains a preferable way to approach dental care than treatment, ${ }^{2,3}$ oral health education has an important place.

Usually, schools would provide an accessible path for delivering such education, however, as per guidelines from the Government, schools are closed to the majority of pupils. Furthermore, those that are attending school are the children of keyworkers who tend to fit into one of two categories: medical professionals or lowerpaid workers. Children of medical professionals are likely to have more at-home guidance on maintaining good dental hygiene, whilst children in lower income groups are disproportionately affected by oral diseases. ${ }^{4,5,6}$ As such, even if schools were willing to have dentists come in to speak to students about oral health, which is unlikely as it poses a risk in and of itself by introducing yet another household to the children, the students that would be taught would not be an accurate representation of the demographic of the country as a whole. Even in the absence of formal schooling, the teaching of children about oral health remains necessary. ${ }^{7,8}$ Finding a representative and diverse group of children whilst social distancing is in place is challenging, but I took it upon myself to contact a local Scout group who, by their own admission, prepare 'young people with skills for life, ${ }^{9}$ to offer a lesson on dental hygiene to their participants. 16th Edgware Scout Group's Beavers and Cubs were continuing to take part in weekly activities over Zoom, and I was able to lead one session.

\section{OHE by Zoom}

A large part of Scouting is the collecting of badges to sew onto your uniform, so determining that participation in my session would contribute towards the scientist and skills badges for Cubs and the health and fitness badges for Beavers ensured a large proportion of the children signed up to 'attend'. Online learning itself poses a number of problems as some learners may not have reliable internet access or may otherwise struggle to participate in online learning. Although this is not such a prevalent problem in first world countries, it is once again those from low socioeconomic backgrounds that are disproportionately disadvantaged. ${ }^{10}$ There is little that $\mathrm{I}$, as an individual, could do to counteract this inequality, but I made sure to distribute the presentation I used after the event so that any participants could look over the information in their own time if they had missed some of the session due to their internet connection dropping. Connectivity issues aside, the effectiveness of online learning is also hotly debated. It seems to be the case that younger children, whom I was speaking to in this instance, struggle with online learning because they tend to require a more structured environment than can be achieved online. ${ }^{11}$ This is even more so the case of children with a weaker academic 

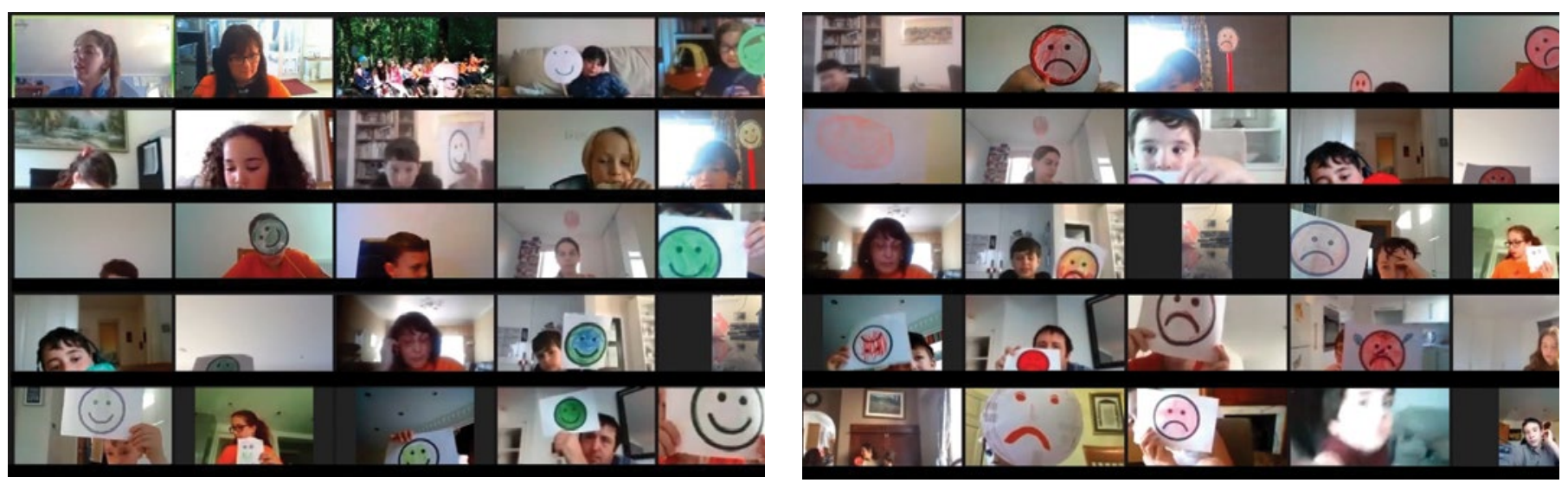

This particular element of the Zoom session with the children involved responding with a happy face or sad face to decide if a particular food was good for your teeth, or bad for your teeth. All photos were taken by the scout leader and used with consent given on behalf of all children by their parents/legal guardians.

\$ background, who, studies suggest, tend to come from lower socioeconomic areas. ${ }^{12}$ On the other hand, by teaching online and organising the session for the evening, parents were able to sit with their children and also have access to the information this is in contrast to school situations which are usually the basis of community initiatives. Ensuring the information could be disseminated directly to the parents will hopefully improve the likelihood of it being taken on board.

Capturing and maintaining the children's attention for an hour was another challenge. With no formal training in teaching, it was important to take advice from those who know best in the area. Thomas ${ }^{13}$ suggests that children work best when allowed to puzzle things out together and often learn most effectively through trial and error. Zoom makes this challenging. I tried to keep these points in mind as I wrote a lesson plan. Using an evidence-based toolkit for prevention, ${ }^{14}$ I created a lesson plan that was engaging and informative. I talked through brushing your teeth, the importance of fluoride and maintaining a healthy diet, three of the four pillars of good oral hygiene that the children would be able to focus on. Combining a quiz, the use of videos and a hands-on activity in which the participants had to measure the amount of sugar they believed to be in various foods and drinks, I produced a lesson that I believed to be both captivating and age appropriate.

Overall, the feedback I received was positive: throughout the Zoom call the children were communicative and responded well to me. Furthermore, the leader of the Scout group has assured me that the lesson was well received and the parents that were present found it insightful too. Whilst I do not have the resources to measure the effectiveness of the lesson, there are other studies on similar programmes. Some evidence questions the longevity of the impact that educational intervention will have had alone $e^{15,16}$ and highlights the importance of education not being a substitute for physical dental care. However, other evidence also points out that there may have been some positive impact, particularly in the short term. ${ }^{17,18}$

It is important to note that not only are children from lower socio-economic backgrounds more likely to need dental treatment, they are less likely to fully benefit from the type of help I can currently offer. It may well be the case that those from deprived backgrounds need more support than online learning. Programmes such as the community development programme that was implemented in two severely socioeconomically challenged pilot districts in Glasgow, UK, showed dental health improvements 'of sufficient magnitude to impact on area-wide statistics. ${ }^{19}$ The idea that a one-size-fits-all approach to dental health education is unlikely to be of much benefit, and tailoring information to the recipient is necessary to enact substantial change.

\section{References}

1. Overview. Dental checks: intervals between oral health reviews. Nice.org.uk. 2004. Available at: https://www.nice.org.uk/guidance/cg19 (accessed 11 June 2020).

2. Treerutkuarkul A, Gruber K. WHO. Prevention is better than treatment. 2015. Available at: https://www.who.int/bulletin/volumes/93/9/15-020915/en/ (accessed 11 June 2020).

3. Richards W. Prevention in practice. Br Dent J 2008; 205: 111.

4. Hobdell M, Oliveira E, Bautista R et al. Oral diseases and socio-economic status (SES). BrDent J 2003; 194: 91-96.

5. Heima M, Ferretti M, Qureshi M, Ferretti G. The effect of social geographic factors on the untreated tooth decay among head start children. J Clin Exp Dent 2017; 9: e1224-e1229.

6. Appleby J, Reed R, Merry L, Root causes: quality and inequality in dental health QualityWatch, 2 November 2017. Available at: https://www.nuffieldtrust.org.uk/ research/root-causes-quality-and-inequality-in-dental-health (accessed 13 July 2020).

7. Kwan S Y L, Peterson P E, Pine C M, Borutta A. Health-promoting schools: an opportunity for oral health promotion. Bull World Health Organ 2005; 83: 677-685.

8. FGDP(UK). FGDP(UK) welcomes new oral health requirement for schools. 19 July 2019. Available at: https://www.fgdp.org.uk/news/fgdpuk-welcomes-new-oral-healthrequirement-schools (accessed 11 June 2020).

9. The Scout Association. 2020. Available at: https://www.scouts.org.uk/about-us/ strategy/ (accessed 11 June 2020).

10. Digital Inequality and Low-Income Households. 2016. Available at: https://www. huduser.gov/portal/periodicals/em/fall16/highlight2.html (accessed 11 June 2020).

11. Loeb S. How effective is online learning? What the research does and doesn't tell us. Education Week, 2020. Available at: https://www.edweek.org/ew/ articles/2020/03/23/how-effective-is-online-learning-what-the.html (accessed 11 June 2020).

12. Thomson $\mathrm{S}$. Achievement at school and socioeconomic background - an educational perspective. NPJ Sci Learn 2018; 3: 5.

13. Thomas A. Children online: learning in a virtual community of practice. E-Learning and Digital Media 2005; 2: 27-38.

14. Department of Health. Delivering better oral health: an evidence-based toolkit for prevention 2017. Available at: https://assets.publishing.service.gov.uk/government/ uploads/system/uploads/attachment_data/file/605266/Delivering_better_oral health.pdf (accessed 11 June 2020)

15. Habbu S, Krishnappa P. Effectiveness of oral health education in children - a systematic review of current evidence (2005-2011). Int Dent J 2014; 65: 57-64.

16. Kay $E$, Locker D. Is dental health education effective? A systematic review of current evidence. Community Dent Oral Epidemiol 1996; 24: 231-235.

17. Calderón Larrañaga S, Expósito Ruiz M, Cruz Vela P et al. Atención Primaria y promoción de la salud bucodental: evaluación de una intervención educativa en población infantil. Atención Primaria 2019; 51: 416-423.

18. White S. Health Matters: Tackling child dental health issues at a local levelPublic health matters. 2017. Available at: https://publichealthmatters.blog.gov. uk/2017/06/19/health-matters-tackling-child-dental-health-issues-at-a-local-level/ (accessed 11 June 2020).

19. Blair Y, Macpherson L, McCall D, McMahon A. Dental health of 5-year-olds following community-based oral health promotion in Glasgow, UK. Int J Paediatr Dent 2006; 16: 388-398. 